\title{
The prevalence of depression and disappointment and their relationship with Substance addiction tendency among high school students in Divandareh City in 2018
}

\author{
Karo Servatyari ${ }^{1}$, Fayegh Yousefi ${ }^{2}$, Pooya Valizadeh Ardalan ${ }^{3}$, Mohammad Aziz Rasouli ${ }^{4}$, Saed \\ Hosseini $^{1}$, Mehdi Ghaderi ${ }^{3}$, Hero Yazdan Panah ${ }^{1}$, Nabi Mardani ${ }^{1}$ \\ 1-Medical Student, Student Research Committee, Kurdistan University of Medical Sciences, Sanandaj, Iran. \\ 2-Associate Professor of clinical psychology, Spiritual Health Research Center, Research Institute for Health \\ Development, Kurdistan University of Medical Sciences, Sanandaj, Iran. \\ 3-BS of laboratory Science, Student Research Committee, Kurdistan University of Medical Sciences, Sanandaj, \\ Iran. \\ 4-MSc Epidemiology, Social Determinants of Health Research Center, Kurdistan University of Medical \\ Sciences, Sanandaj, Iran. \\ Corresponding Author: Hero Yazdan Panah \\ E-mail: Yazdanpanah.hero@yahoo.com
}

Received: 10/06/2019

Accepted: 23/09/2019

\begin{abstract}
Introduction: Depression is one of the most common psychiatric disorders in the general population, which disappointment is the main cause of it, and can lead to addiction. Therefore, by identifying all affecting factors and, all conditions needed to prevent addiction can be provided.

Aim: The purpose of the present study was to determine the prevalence of depression and disappointment and their relationship with Substance addiction tendency among high school students in Divandareh city in 2018.

Method: This is a cross-sectional study. All high school students in Divandareh city included in this study. The sample size was 370 people according to the Morgan table. The sampling method was stratified and the tools were the Beck standard Depression and disappointment Questionnaires and the substance abuse questionnaire. Exclusion criteria included disinclination to participate in the study or incorrect completion of the questionnaires. Data were analyzed by T-test, Spearman correlation and Chi-square tests.

Results: 370 students were included in this study. The prevalence of disappointment in the study was $66 \%$, On the other hand 265 of students had low depression, 79 had moderate depression and 26 students had high levels of depression. There was a significant relationship among disappointment and GPA $(\mathrm{P}=0.012)$, economic status $(\mathrm{P}=0.006)$ and smoking history in students $(\mathrm{P}<0.001)$. Also depression had a significant relationship with age $(\mathrm{P}=0.009)$ and gender $(\mathrm{P}=0.032)$ as well.
\end{abstract}

Conclusion: Depression and disappointment play an important role in quality of life and predict addiction tending in adolescents. And that students studied need more mental health services overall.

Keywords: Depression, Disappointment, Addiction tendency, Students

\footnotetext{
How to cite this article : Servatyari K, Yousefi F, Valizadeh Ardalan P, Rasouli M A, Hosseini S, Ghaderi M, Yazdan Panah H, Mardani N. The prevalence of depression and disappointment and their relationship with Substance addiction tendency among high school students in Divandareh City in 2018. Shenakht Journal of Psychology and Psychiatry. 2019; 6 (5): 1-13. URL: http://shenakht.muk.ac.ir/article-1-716fa.pdf

Copyright $(92018$ the Author (s). Published by Kurdistan University of Medical Sciences. This is an open access article distributed under the terms of the Creative Commons Attribution-Non Commercial License 4.0 (CCBY-NC), where it is permissible to download, share, remix, transform, and buildup the work provided it is properly cited. The work cannot be used commercially without permission from the journal.
} 


\section{بررسى شيوع افسردكى و نااميدى و رابطه آن بر كرايش به سوءمصرف مواد مخدر در دانش

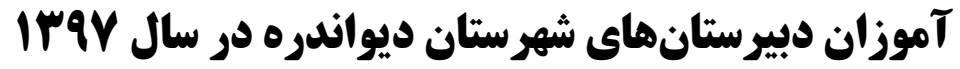

كارو ثروت يارى'، فايق يوسفى'، بويا واليزاده اردلانّ، محمد عزيز رسولى'، ساعد حسينى'، مهدى قادرى'، هيرو

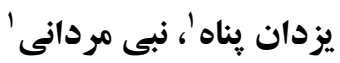

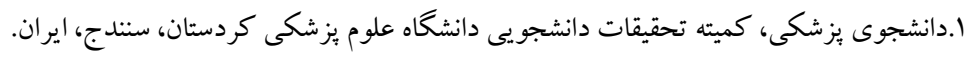

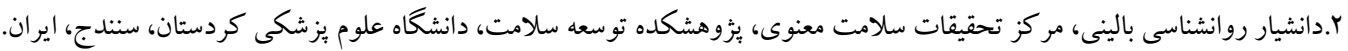

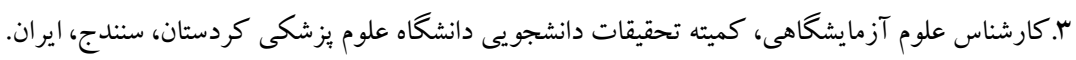

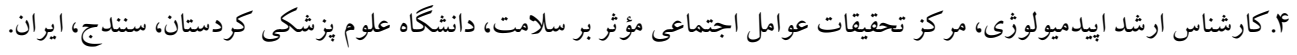
ايميل:yazdanpanah.hero@yahoo.com مولف مسئول: هيرو يزدان يناه

مقدمه: افسردگى يكى از شايع ترين اختلالات روانى در جمعيت عمومى است كه ناميدى عامل اصلى آن است و مى تواند سبب

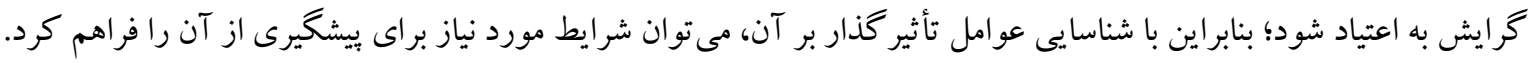
هدف: هدف از مطالعه حاضر، تعيين شيوع افسردگى و ناميدى و رابطه آن بر گرايش به سوءمصرف مواد مخدر در دانش آموزان

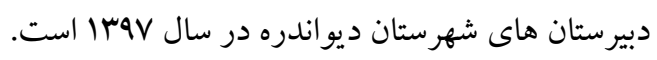
روش: مطالعه حاضر مقطعى است. جامعه آمارى شامل دانش آموزان مقطع دبيرستانى شهرستان ديواندره و حجم نمونه مطابق

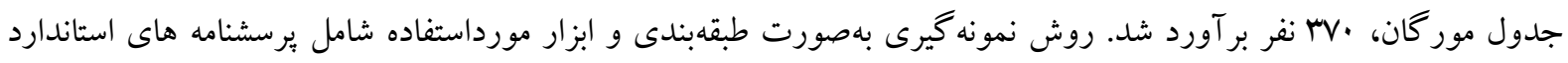

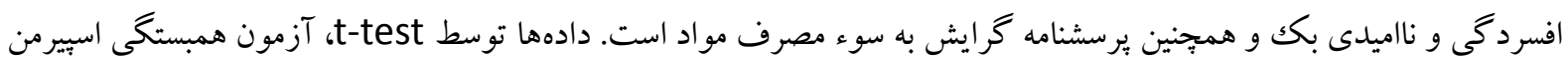

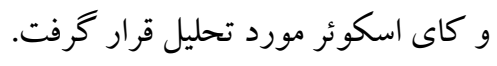

يافته ها: در مطالعه حاضر شيوع ناميدى در مطالعه حاضر 99 درصد بود از سوى ديخر، ذ9 به نفر از دانش آموزان داراى ميزان

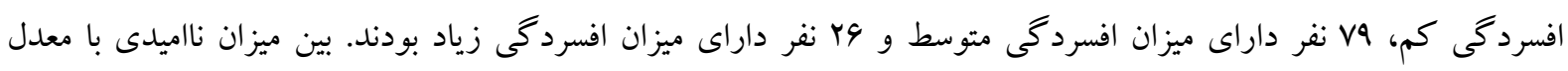

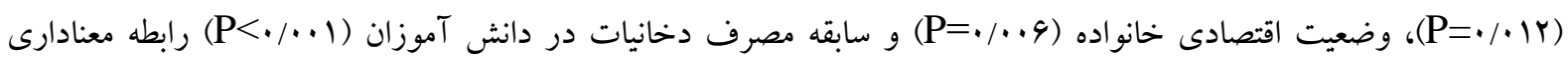

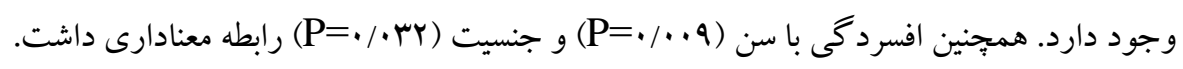
نتيجه كيرى: يافتها دلالت بر اين دارد كه افسردگى و ناميدى نقش مهمى در كيفيت زنـدگى و بيشيينى آمادكى به اعتياد

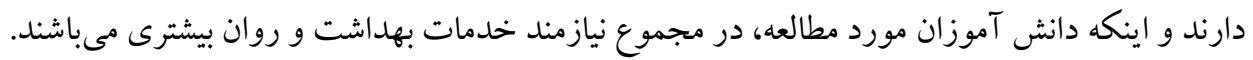
كليدوازه ها: افسردگى، ناميدى، گُ ايش به اعتياد، دانش آموزان 
كار اتفاق مىافتد. در دنيا حدود |Y| ميليون نفر مبتلا به

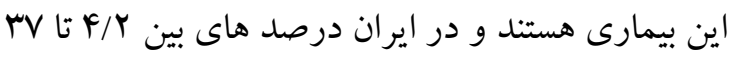

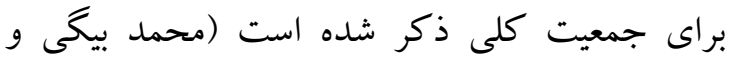

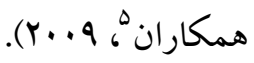
بك ناميدى را عامل اصلى افسردگى مى داند كه مى هـ تواند باعث عواقب زيادى در فرد از جمله تضعيف اراده، عدم تحمل موقعيتهاى مختلف، مشكلات رفتارى، سوءمصرف مواد و افزايش احتمال اقدام به خود كشى مىشود. اتفاقات منفى زندگى مثل بيكارى و بيمارى مىتواند سبب ناميدى شود. امروزه افزايش مشكلات و درگيرى هاى روانى باعث افزايش شيوع ناميدى شده كه اين موضوع را قابل اهميت تر از كذشته ساخته است (مايس آليس و همكاران?؛ (1919). افسردگى و نااميدى سبب كاهش كيفيت و كميت

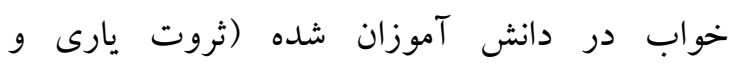

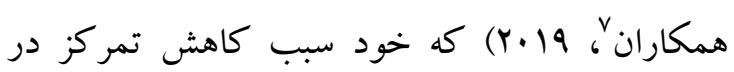
كلاس درس خواهد شد (ثروت يارى و همكاران،

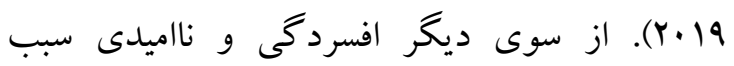
افزايش اعتياد به تلفن همراه و عوارض ناشى از آن مى شود (ثروت يارى و همكاران، 19 •r). اعتياد يكك حالت فراخير است كه هيج كشورى از خطر آن در امان نيست. عوارض ناشى از اعتياد در كشورهاى در حال توسعه مثل ايران كه نياز بيشترى به اله نيروى انسانى جهت دستيابى به هدفهاى پيايهاى و اصلى دارند ضرر بيشترى دارد (مدبرنيا و همكاران؛

( $(r \cdot 1)$

اعتياد به مواد مخدر يكك اختلال روانى مزمن است كه

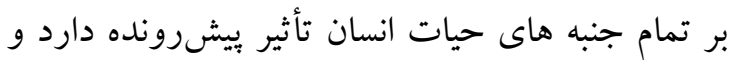

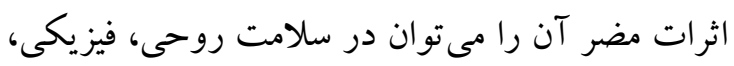

5 - Mohammad Beigi et al

${ }^{6}$ - Mayes Alice et al

7 - Servatyari et al

8 - Moddabernia et al

\section{مقلهم}

افسردگى يكى شايعترين اختلالات روانى در جمعيت عمومى است و شامل غم و اندوه، از دست دادن علاقه يا لذت، احساس گَناه يا كاهش اعتماد به نفس، اختلال خواب يا اشتها، احساس خستخى و در شديدترين حالت سبب خودكشى خواهد شد. مشخص مىشود. سازمان جهانى بهداشت فراوانى افسردگى راد در جهان Y YMM ميليون نفر برآورد كرده كه تقريباً نيمى از اين افراد در جنوب شرق آسيا و غرب منطقه اقيانوس آرام

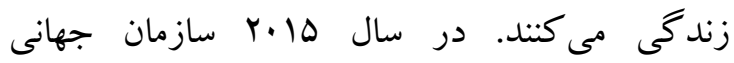
بهداشت، شيوع افسردىى را در جهان F/F درصد بر آورد كرده كه اين نسبت در زنان (1/ه./)، بيشتر از

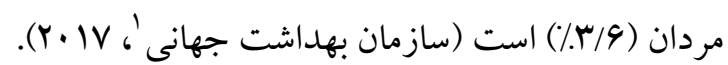

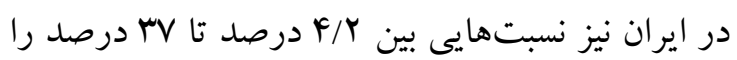
در مطالعات مختلف براى اختلال روانى افسردگى

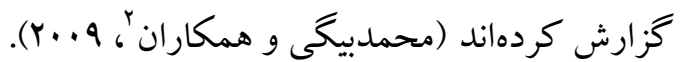
بيمارى هاى روان مجموعهى بسيار وسيعى را شامل مىشود كه افسردگى شايعترين آنها در جهان و ايران است به طورى كه · إدرصد افراد حداقل يككبار در زندگى شان دجار افسردگى شدهاند. اين بيمارى صرف نظر از نزاد، طبقه و موقعيت اجتماعى مى توانند در هر

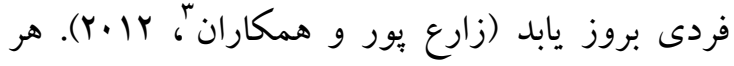

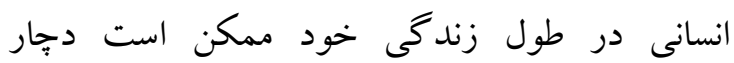
افسردگى شود كه مىتواند نشانهاى متفاوتى از قبيل احساس بى ارزشى، غم و اندوه مداوم، اختلال در

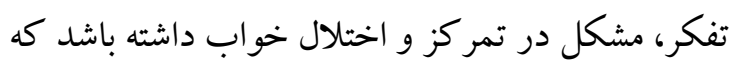
مى تواند سلامت جسم و روح انسان را به خطر بيندازد

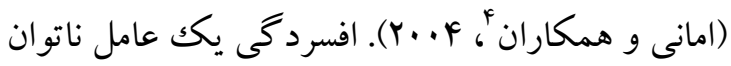
كننده در دنياست كه حدود •ه درصد آن در محيط

- World Health Organization

2 - Mohammad Beigi et al

3 - Zarepoor et al

4 - Amani et al 
بيشخيرى از آن فراهم شود (مدبرنيا و همكاران، r. r روند متحول شدن ساختار روانى انسان، از مهمترين مسائل دوران حيات اوست كه بيشترين تغيير آن از بدو تولد تا آخر دوران جوانى است. از ديدگاه اريكسون،

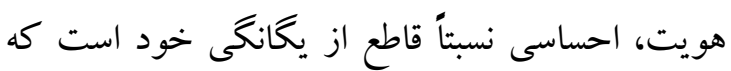
هر جه اين احساس هويت بيشتر باشد، فرد با آمادكى و و هو قاطعيت بيشترى با مشكلات و و مسائل دوران

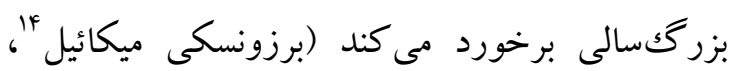

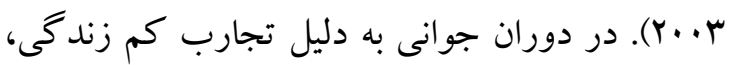

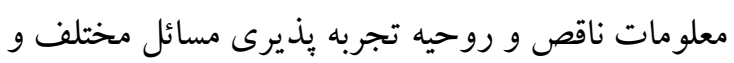
همجنين تأثيريذيرى بيشتر از همسالان كرايش به به مواد بهري

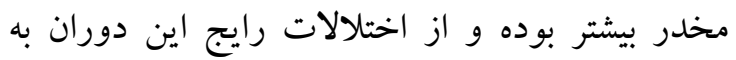

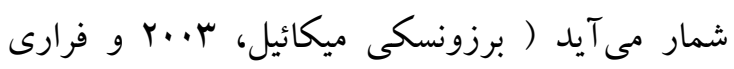
جوزف 10، 1999).

با توجه به مطالعات انجام شده، مشخص شده كه كورج

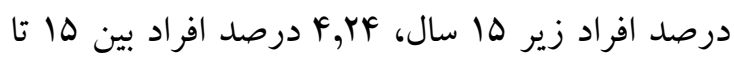

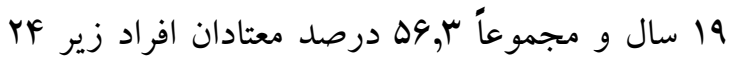

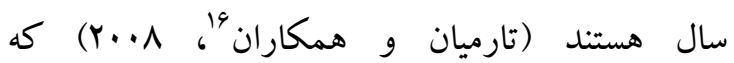
نشاندهنده مهم بودن مسئله اعتياد در اين برهه سنى حساس است. با توجه با اهميت معضل اعتياد و نقش مخربى كه بر جامعه دارد، نياز به تحقيق بيشتر براى شناسايى آن و همجنين اقدام در جهت كاهش آن بسيار ضرورى است. با توجه به اينكه در جهت يافتن ارتباط بين افسردگى و نااميدى با گرايش به اعتياد در در دانش

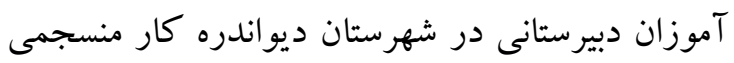
به جشم نمى خورد، لذا تحقيق در اين زمينه را حائز

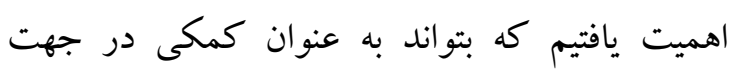

14 - Berzonsky Michael

15 - Ferrari Joseph

16 - Taremian et al
اجتماعى، احساسى و شناختى بيمار به طور واضح

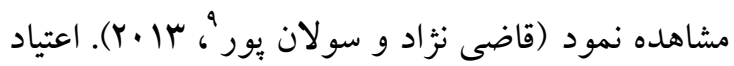
در همه سطوح اجتماعى، تحصيلى، شغل ها و فرهنگ

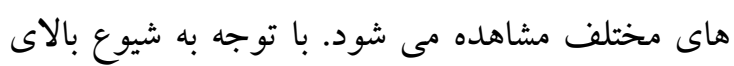
مصرف مواد و دشوارى درمان آن، تلاش براى شناختن

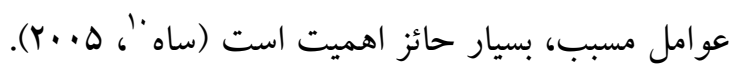
در سال هاى اخير افزايش استفاده از مواد مخدر، كاهش سن مصرف، يديدار شدن بيمارىهاى مختلف

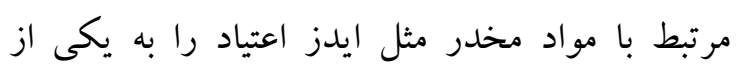

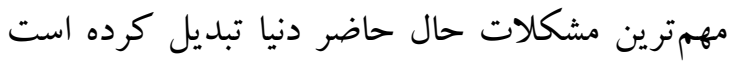

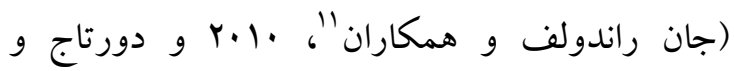

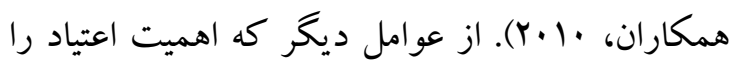
بالا مىبرد، جرم و جنايت ناشى از آن مثل خودفروشى، آدم كشى و دزدى در جهت تأمين هزينه مواد مخدر است. در مطالعهاى عنوان شده كه حدود .9. معتادان مجدداً به مصرف مواد روى مى آورند جون در مر مراكز

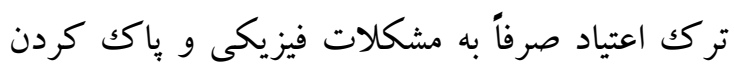

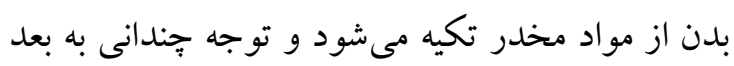

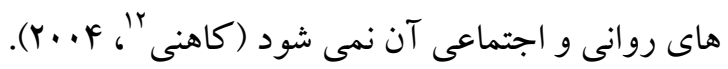

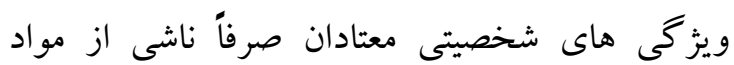
مخدر نيست بلكه ريشه در اختلالات و نارسايىهاى روانى قبل اعتياد دارد كه بعد از اعتياد تشديد مىشود.

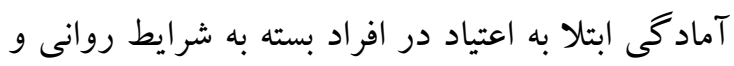

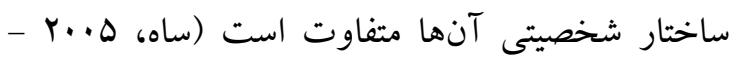

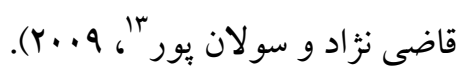
طيف گستردهاى از شرايط درونى و بيرونى فرد بود مىتواند در گرايش به اعتياد تأثير داشته باشد كه بارئ برنامهريزى جامع و كلى مىتوان شر ايط مورد نياز براى بـ بله

\footnotetext{
9 - Ghazinezhad, Savalanpour

10 - Saah

11 - Jon Randolph et al

12 - Kaheni

13 - Ghazinezhad and Savalanpour
} 


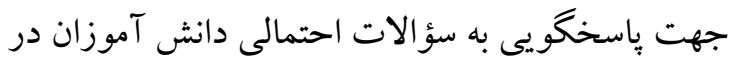
كلاس درس حاضر شد.

ابزار

ابزارهاى اين يُزوهش، : يرسشنامه حاوى اطلاعات

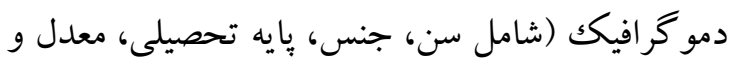
وضعيت تحصيل، وضعيت اقتصادى خانو اده، وضعيت مصرف دخانيات) بود. يرسشنامهاى مورد استفاده شامل " برسشنامه زير بود.

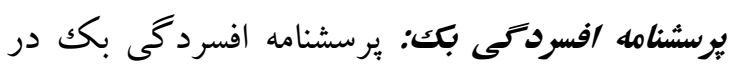

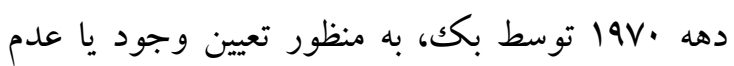
وجود افسردى و شدت آن در جوانان و نوجوانان طراحى گرديد. آزمون افسردگى بك شد شدت حالت

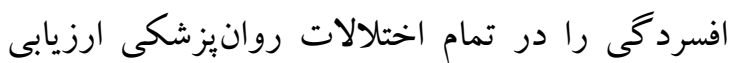
مى كند و كاربرد مناسبى در ارزيابى رواندرمانى و ميزان تأثير درمانهاى مختلف روى بيمار دارد. اين

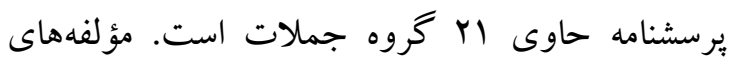
برسشنامه شامل اب مؤلفه زير است.

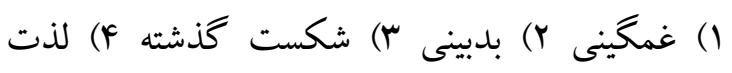
نبردن ه) احساس كناه 9) احساس تنبيه V) دوست نداشتن خويش ^) خود انتقادى 9) افكار خود كشى يا تمايل به خود كشى •() گريه كردن (1)) بع قرارى r|)

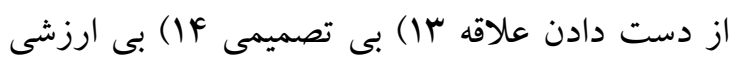
ها) از دست دادن انرزى (19) تغيير در الكوى خواب

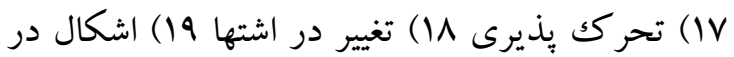

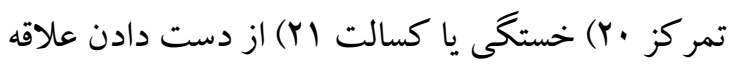

نمره كذارى يرسشنامه بر اساس طيف ليكرت جهار

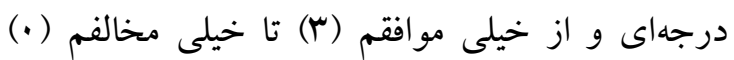
بوده و تحليل (تفسير) بر اساس ميزان نمره يرسشنامه، به

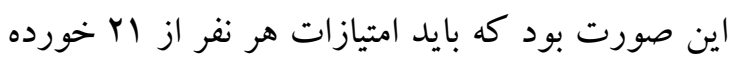

كنترل اعتياد، در اختيار سازمان ها و نهاد هاى مربوطه

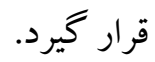
در اين مطالعه به بررسى تأثير دو عامل افسردگى و وري نااميدى در خرايش نوجوانان دبيرستانى شهرستان ديواندره به سو مصرف مو اد مخدر يرداخته مى شود.

\section{روش}

اين مطالعه به روش مقطعى از نوع تحليلى انجام شد. جامعه آمارى مورد مطالعه دانش آموزان مقطع متوسطه

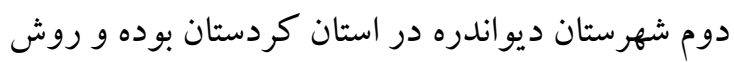
نمونه كيرى به صورت طبقه بندى و داخل هر طبقه به دونه

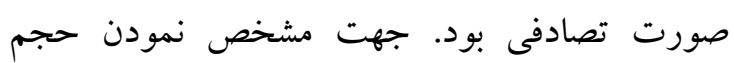

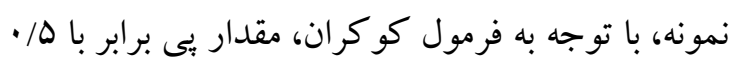

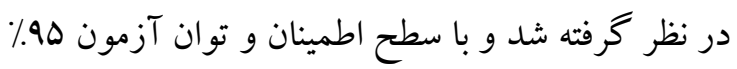
حجم نمونه ·rV نفر برآورد گرديد. معيار ورود به مطالعه شامل دانش آموزان 19-19 ساله ساكن شهرستان ديواندره در كليه رشتها و كليه مدارس و معيار خروج از مطالعه شامل، عدم علاقه به تكميل

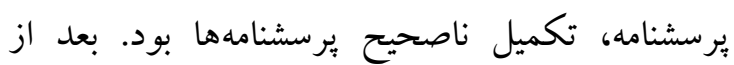

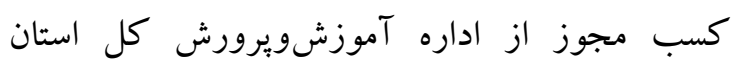
كردستان و موافقت مديران مدارس انتخابشده و با مجرون دانش آموزان هر مدرسه انتخاب شده در مورد اهداف يُزوهش ارائه مىشود و يس از اخذ رضايت آكاهانه از كليه دانش آموزان مبنى بر تكميل اطلاعات مندرج در برد يرسشنامه ضمن دعوت از آنان براى شركت در مطالعه

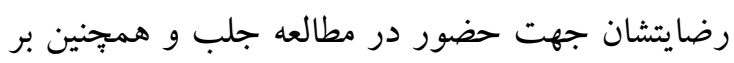
محفوظ ماندن كل اطلاعات مربوط به آنان تأكيد كرديد. برسشخران آموزش ديده طبق برنامه زمانى از اط قبل تعيين شده در مدارس حضور يافتند و در يكى از كلاسهاى درس، سؤالات يرسشنامه را براى دانش

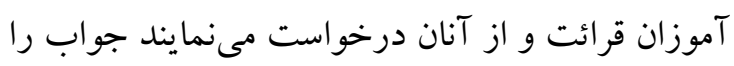

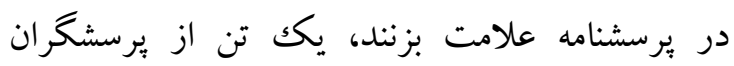


درست بود). در مرحله بعد نمرات سه زير مقياس اين يرسشنامه استخراج گرديد

-در صورتى كه نمرات برسشنامه بين · تا ب باشد، ميز ان ناميدى در حداقل است. - در صورتى كه نمرات برسشنامه بين F تا م باشد، ميزان ناميدى در سطح خفيف است. - در صورتى كه نمرات يرسشنامه بين 9 تا fl باشد، ميز ان ناميدى در سطح متوسط است. - در صورتى كه نمرات برسشنامه بين ها تا •ب باشد، ميزان ناميدى در سطح شديد است. اين برسشنامه در ايران در مطالعات مختلف بر روى نوجوانان استفاده شده و روايى و بايايى آن سنجيده

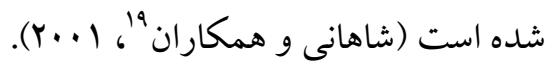
يرسشنامه آمادكى به اعتياد: اين :برسشنامه، مقياس ايرانى آمادكى به اعتياد است كه با توجه به شرايط

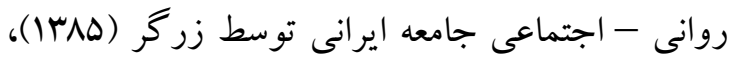

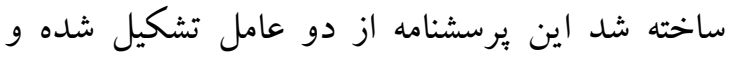
داراى 4\$ ماده به اضافه ه ماده دروغ سنج است. اين يرسشنامه تركيبى از دو عامل آمادگى فعال و

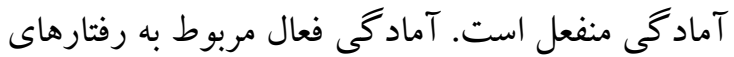

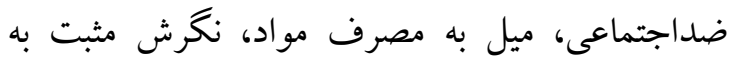
مو اد، افسردگى و هيجان خواهى است و در عامل دوم (آمادگى منفعل) بيشترين مادهها مربوط به عدم ابراز

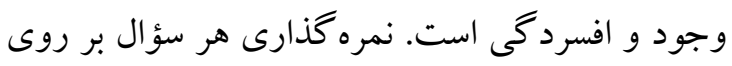
يكك ييوستار از صفر (كاملاً مخالفم) تا ب م (كاملاً موافقم) است. البته اين شيوه نمره گذارى در سؤالات

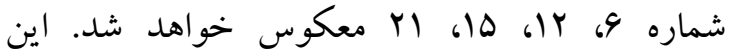
يرسشنامه داراى عامل دروغسنج است كه شامل

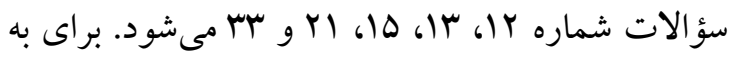
دست آوردن امتياز كلى :برسشنامه بايد مجموع امتيازات تككتكك سؤالات (به غير از مقياس دروغ
مقياس باهم جمع مىشد. حداقل امتياز ممكن · و حداكثر سو بود. نمره بين · تا آץ: نشاندهنده ميزان افسردگى ضعيف در جامعه بود. نمره بين ال تا اسب: نشاندهنده ميزان افسردگى متوسط

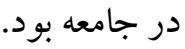
نمره بالاتر از اس: نشاندهنده ميزان افسردگى زياد در

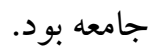
كاويانى و موسوى با اجراى اين برسشنامه در ايران،

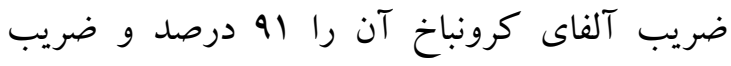
باز آزمايى به فاصله يكك هفته آن را، أه درصد گز ارش

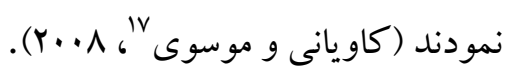
يرسشنامه نا/ميلى بك: اين برسشنامه داراى ·r سؤ ال بوده و هدف آن بررسى سه بعدى ناميدى فرد

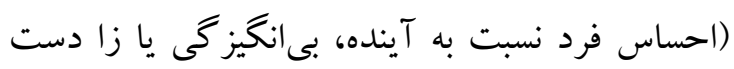
دادن انخيزه و انتظارات) بود. بك از ناميدى به عنوان علامت هسته اى افسردگى ياد نموده و يادآور مى شود كه اين ناميدى هم فلج كننده اراده است و هم باعث تحمل نايذيرشدن و ميل به گريز از يكك موقعيت مى گردد (بكك آرون و همكاران^؛ (19VF

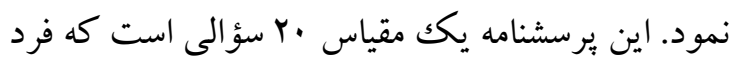

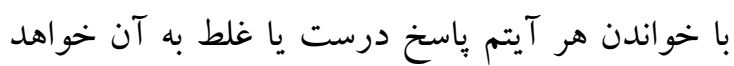
ديد. اين برسشنامه سه بعدى ناميدى فرد را مىسنجد و

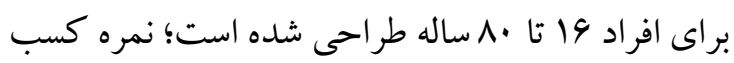
شده در آن بين · تا • Yا است كه نمره بالاتر نشانه ناميدى بيشتر است.

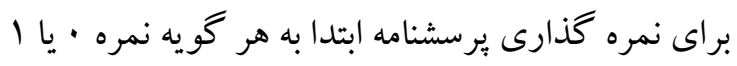

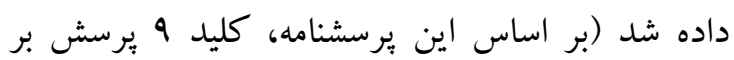

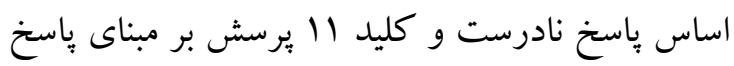

\footnotetext{
${ }_{17}^{17}$ - Kaviani and Mousavi

18 - Beck Aaron et al
} 
درصد (VYY نفر) دختر بودند. ميانكين و انحراف معيار سنى شر كت كنند كان، 19/11 + 1919 بود.

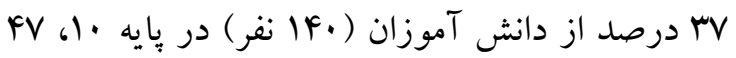

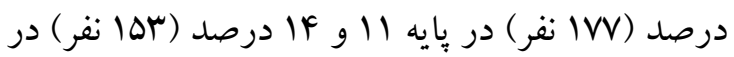
يايه r ا مشغول تحصيل بودند. شيوع نااميدى در مطالعه حاضر 49 درصد بود كه از اين ميان، ·F درصد (Fq F نفر) ميزان ناميدى كم، 19 درصد (VY نو ) ميزان نااميدى متوسط و ه درصد (Y) نفر) ميزان نااميدى شديدى داشتند. از سوى ديخر در مطالعه حاضر، VI درصد (S90 نفر) از دانش آموزان داراى ميزان افسردگى كم، الب درصد (Vq نفر) داراى ميزان افسردگى متوسط و V درصد (Y) نفر) داراى ميز ان افسردگى زياد بودند. بر اساس نتايج آزمون همبستخى اسيرمن، بين سن و ميزان افسردگى رابطه معنادارى يافت شد (9 ( + (P). اما بين سن و نااميدى رابطه معنادارى يافت شد $(\mathrm{P}=\cdot / \wedge \wedge \varphi)$

در جدول شماره ا نشان داده شده است كه بين سطوح مختلف افسردگى با معدل (سr// اقتصادى خانواده ( در دانش آموزان (191) ندارد ولى افسردگى با جنسيت رابطه معنادارى داشت $(\mathrm{P}=\cdot / \cdot r r)$
سنج) را با هم جمع نمود. اين نمره دامنهاى از • تا ^• 1 را خواهد داشت. نمرات بالاتر به منزله آمادكى بيشتر فرد ياسخ دهنده براى اعتياد مى باشند. نمره بين · تا وب

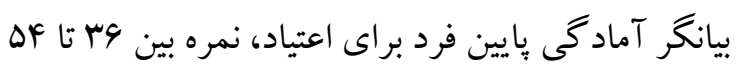
بيانگر آمادگى متوسط فرد براى اعتياد و نمره بالاتر از ها بيانگر آمادكى بالاى فرد براى اعتياد است. در يزوهش زرگر و همكاران، اعتبار يرسشنامه با روش آلفاى كرونباخ •9/ • محاسبه شد كه در حد مطلوب

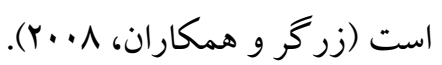
در انتها داده جهت تجزيهوتحليل آمارى به نرم افزار SPSS_ ورزن 19 وارد و مورد آناليز آمارى قرار كرفت. جهت بررسى دادههاى توصيفى از آمار

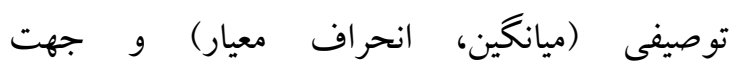
تجزيهوتحليل دادههاى تحليلى در صورت نرمال بودن دادهها از آزمون كاى اسكوئر و t-test و در صورت غير نرمال بودن داده ها، از آزمون من ويتنى و كروسكال واليس استفاده شد. براى تمام آزمون ها سطح معنادارى برابر ه. در نظر كرفته خواهد شد. براى تمامى بارامترهاى ذكر شده حدود اطمينان هذ\%٪ نيز محاسبه خو اهد شد.

\section{كافته ها}

در مطالعه حاضر، از ·rV نفر دانش آموز دبيرستانى شهرستان ديواندره، OF درصد (191 نفر) بسر و

جدول 1 بررسى رابطه بين سطوح مختلف افسردكى با برخى از متغير هاى دمو كر افيك

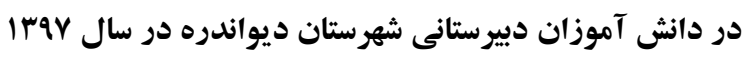

\begin{tabular}{|c|c|c|c|c|c|c|}
\hline \multirow{2}{*}{ معنادارى سطح } & \multirow{2}{*}{ (درصد) } & \multicolumn{3}{|c|}{ ميزان افسردىى } & & \\
\hline & & افسردگى زياد & افسردگى متوسط) & افسردگى كم (درصد) & & \\
\hline \multirow[t]{3}{*}{ 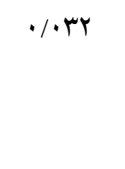 } & $191(\Delta r / \Delta)$ & $q(\mu F / 9)$ & FI $(\Delta 1 / 9)$ & $\operatorname{If\wedge }(\Delta \Delta / \Lambda)$ & مرد & \multirow[t]{3}{*}{ جنسيت } \\
\hline & $\operatorname{lVr}(F q / 0)$ & $\operatorname{IV}(9 \Delta / 4)$ & $\Gamma_{\Lambda}(F \wedge / I)$ & $11 V(F F / Y)$ & زن & \\
\hline & $r v \cdot(1 \ldots)$ & rq $(1 \ldots)$ & va $(1 \ldots)$ & $r 90(1 \ldots)$ & & \\
\hline \multirow[t]{2}{*}{ מ } & $\operatorname{IrF}(r q / Y)$ & If $(\Delta r / \Lambda)$ & $r \cdot(r V / q)$ & $q \cdot(r / q)$ & نامناسب & \multirow[t]{2}{*}{ معدل } \\
\hline & rMG (GT/A) & Ir $(F q / r)$ & $k q(q Y / 1)$ & IVD $(99 / 1)$ & مناسب & \\
\hline
\end{tabular}




\begin{tabular}{|c|c|c|c|c|c|c|}
\hline & $r v \cdot(1 .)$. & rg $(1 \ldots)$ & va $(1 \ldots)$ & $r 90(1 \ldots)$ & & \\
\hline \multirow[t]{4}{*}{$\cdot|F F|$} & $r \cdot l(\Delta F / r)$ & $\operatorname{lr}(\Delta \cdot)$ & $\operatorname{Rr}(\Delta r / r)$ & IF\& $(\Delta \Delta / r)$ & نامناسب & \multirow[t]{3}{*}{ اقتصادى } \\
\hline & $1 \mathrm{H}^{-}(\mathrm{rq} / \mathrm{V})$ & $q(r y / 9)$ & $r \wedge(r \Delta / F)$ & $৭ ৭(r V / r)$ & متوسط & \\
\hline & r $(\wedge)$ & $f(1 \Delta / F)$ & $9(11 / 4)$ & $r \cdot(V / \Delta)$ & مناسب & \\
\hline & $r v \cdot(1 \ldots)$ & $r q(1 \ldots)$ & va $(1 \ldots)$ & $r 90(1 \ldots)$ & & \\
\hline \multirow[t]{3}{*}{$\cdot 191$} & $\operatorname{lIV}(r \mid / 9)$ & $q(r / M)$ & ro $\left(\mu_{1 / 9}\right)$ & $\Lambda \&(r r / \Delta)$ & دارد & \multirow[t]{3}{*}{ اعتياد } \\
\hline & $\operatorname{ror}(9 \Lambda / F)$ & $r \cdot(V q / 9)$ & $\Delta F(G \wedge / \Gamma)$ & IVq $(9 V / 0)$ & ن ندارد & \\
\hline & $r v \cdot(1 \ldots)$ & $r 4(1 .)$. & va $(1 \ldots)$ & r9s (1...) & & \\
\hline
\end{tabular}

آموزان ( (P</ ) رابطه معنادارى وجود دارد؛ اما بين جنسيت با ميزان ناميدى رابطه معنادارى يافت نشد

$$
.(\mathrm{P}=\cdot / 91)
$$

در جدول شماره Y، نشان داده شده است كه بين ميزان ناميدى با معدل (Y=//P)، وضعيت اقتصادى خانو اده (4. • (P= و و سابقه مصرف دخانيات در دانش

جدول ץ بررسى رابطه بين سطوح مختلف ناميدى با برخى از متغير هاى دمو كر افيكك

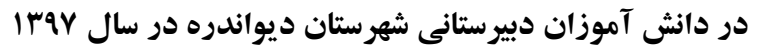

\begin{tabular}{|c|c|c|c|c|c|c|c|}
\hline \multirow{2}{*}{ معنادارى سطح } & \multirow{2}{*}{ (درصد) } & \multicolumn{4}{|c|}{ ميزان نااميدى } & & \\
\hline & & ناميدى زياد & ناميدى متوسط & ناميدى كم & ناميدى ندارد & & \\
\hline \multirow[t]{3}{*}{. /9 } & $19 \Lambda(\Delta r / \Delta)$ & $\operatorname{Ir}(\Delta F / \Delta)$ & fq $(q \pi / q)$ & $\operatorname{Ar}(\Delta \Delta)$ & $\Delta \Lambda(F \Delta / v)$ & مرد & \multirow[t]{2}{*}{ جنسيت } \\
\hline & $\operatorname{IVr}(r q / 0)$ & 1. $(\kappa F / \Delta)$ & rq $(r q / 1)$ & $q V(F \Delta)$ & $9 q(\Delta F / r)$ & زن & \\
\hline & $r v \cdot(1 \ldots)$ & $r r(1 \ldots)$ & $\operatorname{vr}(1 \cdots)$ & $1 F q(1 \ldots)$ & $\operatorname{lrv}(1 \ldots)$ & & \\
\hline \multirow[t]{3}{*}{$\cdot / \cdot 1 r$} & $\operatorname{IrF}(r G / Y)$ & If $(9 \pi / 9)$ & rq $(r 4 / 1)$ & $\Delta \Lambda(r \wedge / q)$ & rq (rA/r) & 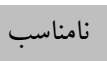 & \multirow[t]{3}{*}{ معدل } \\
\hline & rmg (gr/A) & $\wedge(r q / F)$ & $4 q(q \pi / 9)$ & $91(91 / 1)$ & $91(V I / v)$ & مناسب & \\
\hline & $r V \cdot(1 \ldots)$ & $r Y(1 \cdots)$ & $V r(1 \ldots)$ & Ifq (1...) & $\operatorname{lrv}(1 \ldots)$ & & \\
\hline \multirow[t]{4}{*}{$\cdot 1 \cdot .9$} & $r \cdot 1(\Delta F / r)$ & $19(V / V)$ & $r V(\Delta \mid / F)$ & $M(\Delta q)$ & q. $(F V / Y)$ & 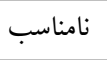 & \multirow[t]{3}{*}{ اقتصادى } \\
\hline & IrG (ra/v) & $\Delta(Y Y / V)$ & $r \cdot(r V / V)$ & $\Delta r(r \Delta / \Delta)$ & $\Delta \wedge(F \Delta / v)$ & متوسط & \\
\hline & (9) & $1(f / 9)$ & $10(r \cdot / 9)$ & $\wedge(\Delta / \Delta)$ & $9(V / l)$ & مناسب & \\
\hline & $r v \cdot(1 \ldots)$ & $r r(1 \cdots)$ & $\operatorname{Vr}(1 \ldots)$ & Ifq $(1 \ldots)$ & $\operatorname{lrv}(1 \ldots)$ & & \\
\hline \multirow[t]{3}{*}{$\cdot / \cdots 1$} & $11 V(r / / 9)$ & $11(0 \cdot)$ & $r r(r \cdot / \Delta)$ & $g r(F / / 9)$ & $r Y(I V / r)$ & دارد & \multirow{3}{*}{ سابقه مصرف } \\
\hline & $\operatorname{ror}(q \wedge / F)$ & $11(0 \cdot)$ & $\Delta \cdot(99 / 0)$ & $\Lambda V(\Delta \Lambda / F)$ & $1 \cdot \Delta(\wedge r / V)$ & ن & \\
\hline & $r v \cdot(1 \ldots)$ & $r r(1 \ldots)$ & $V r(1 \ldots)$ & $1 F q(1 \ldots)$ & $\operatorname{IrV}(1 \ldots)$ & & \\
\hline
\end{tabular}

$(\mathrm{P}</$. Iر دانش آموزان، رابطه مستقيم و معنادارى از سوى ديخر، با توجه به نتايج آزمون كاى اسكوئر، داشت. (جدول شماره rو F)

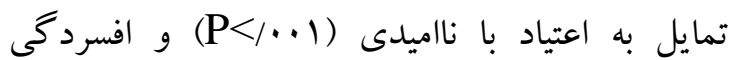

جدول × بروسى رابطه بين ميزان نااميدى با تمايل و كر ايش به اعتياد

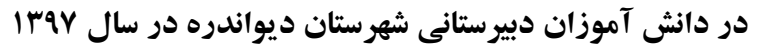

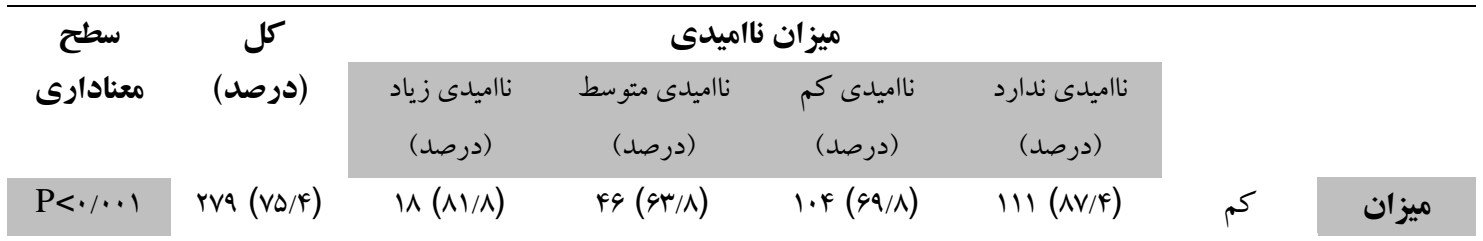




\begin{tabular}{|c|c|c|c|c|c|c|}
\hline $99(\mathrm{IV} / \mathrm{A})$ & $r(9 / 1)$ & $\mathbb{1 r}(1 \mathrm{~N} / \mathrm{l})$ & $r V(Y F / \Lambda)$ & If (11) & متوسط & اعتياد \\
\hline$r \Delta(\varepsilon / \Lambda)$ & $r(9 / 1)$ & Ir (1N/I) & $\wedge(\Delta / \varphi)$ & $r(1 / 9)$ & زياد & \\
\hline$r v \cdot(1 \ldots)$ & $r r(1 .)$. & $V r(1 \ldots)$ & lfq $(1 \ldots)$ & $\operatorname{Irv}(1 \ldots)$ & & \\
\hline
\end{tabular}

جدول † بررسى رابطه بين سطوح مختلف افسردكى با تمايل و كرايش به اعتياد

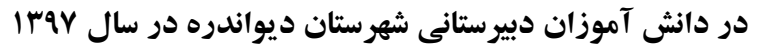

\begin{tabular}{|c|c|c|c|c|c|c|}
\hline \multirow[t]{2}{*}{ سطح معنادارى } & \multirow[t]{2}{*}{ كل (درصد) } & \multicolumn{3}{|c|}{ ميزان افسردكى } & \multirow[b]{3}{*}{ 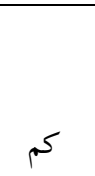 } & \multirow{4}{*}{ اعمايل به } \\
\hline & & زياد (درصد) & متوسط (درصد) & كم (درصد) & & \\
\hline \multirow{4}{*}{$\mathrm{P}<\cdot / \cdot \cdot 1$} & rVq $(V \Delta / F)$ & $1 \cdot(r \wedge / \mathcal{F})$ & $\Delta r(q V / l)$ & ris $(\Lambda 1 / \Delta)$ & & \\
\hline & $99(\mathrm{IV} / \mathrm{A})$ & $\operatorname{Ir}(F q / 1)$ & $r \cdot(r \Delta / r)$ & $\operatorname{rF}(I Y / \Lambda)$ & متوسط & \\
\hline & $r \Delta(\xi / \Lambda)$ & $f(\mid \Delta / f)$ & $4(V / 9)$ & $10(\Delta / V)$ & 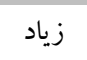 & \multirow[b]{2}{*}{ كل } \\
\hline & $r v \cdot(1 \ldots)$ & rq $(1 \cdots)$ & $\operatorname{va}(1 \ldots)$ & r90 $(1 \ldots)$ & & \\
\hline
\end{tabular}

همكاران، اسنايدر و همكاران همسو بود (سيرس "r

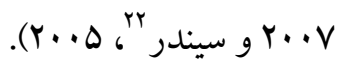

طبق جدول r بين وضعيت اقتصادى خانواده

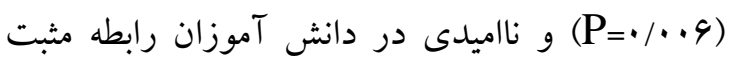
معنى دارى يافت شد به گونهاى كه در دانش آموزانى كه نشاط، شادابى و اميد به آينده در آنها كمتر ديده مى شد، داراى وضع اقتصادى خانوادگى نامناسبى بودند

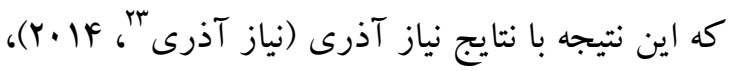
همسو بود. همجنين بين سابقه مصرف دخانيات در دانش آموزان (1) وجود داشت به اين معنى كه دانش آموزان ناميد دركذشته حداقل يكك بار به دخانيات روى آوردهاند؛ كه با تحقيق شهرام محمد خانى و همكاران

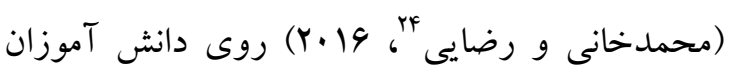
متوسطه شهرستان نجف آباد انجام شد، همخوانى دارد. طبق نتايج آنان نااميدى با مصرف سيگار در طول عمر و مصرف سيگار در يك ماه كذشته و تمايل به مصرف قليان رابطهى معنادارى دارد. ديخر مطالعات نيز به اين
يثزوهش حاضر نشان داد شيوع نااميدى در دانش آموزان شهرستان ديواندره به عنسوان جمعيتى غيربـالينى قابـل ملاحظه است. شيوع ناميدى در مطالعه

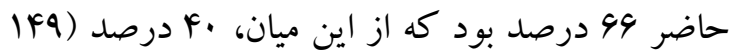
نفر) ميزان نااميدى كم، 19 درصد (VY نفر) ميزان ناميدى متوسط و ه درصد (Y (Y نفر) ميزان نااميدى شديلدى داشتند. در جدول شماره r، نشان داده شده است كه بين ميزان نااميدى با معدل (Y ( P=/ P)، رابطه معنى دارى وجود دارد كه اين نتيجه با مطالعه على عيسى زادگان و همكاران در ايران كه رابطه بين اميد و خوش بينى را با عملكرد تحصيلى دانش آموزان دوره بيش دانشگاهى بررسى كرده بودند، همسو بود. آنان دريافتند كه بين اميد، خوش بينى و عملكرد تحصيلى دانش آموزان رابطه مثبت معنى دارى وجود دارد (عيسازادگان و

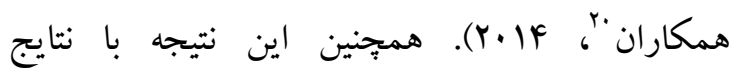
تحقيقات انجام شده در خارج كشور از جمله سيرز و 
رابطه آمارى معنادارى بين جنسيت و ديخر اختلالات روانيزشكى از جمله اختلال نافرمانى مقابلهاى در

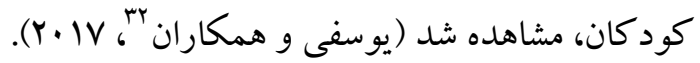

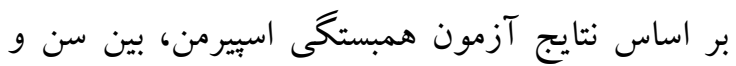

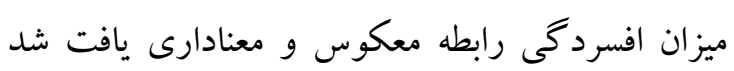

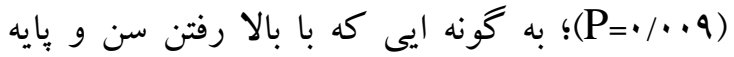

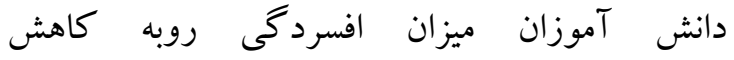

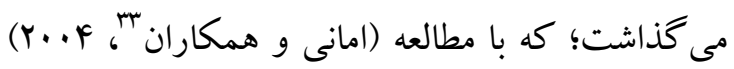
امانى و همكاران همسو بود. اما بر اساس همين آزمون

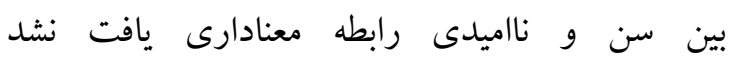
( $(\mathrm{P}=\cdot / \wedge \wedge \varphi)$ از سوى ديخر، طبق جدول سا، با توجه به نتايج آزمون

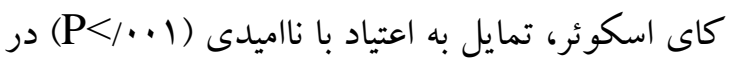
دانش آموزان، رابطه مستقيم و معنادارى داشت. اين نتيجه با نتايج مطالعات محسنى و همكاران (محسنى و

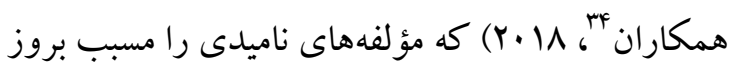
رفتارهاى برخطر شامل گرايش به مواد مخدر در نوجو انان مى دانست همسو است. در مطالعه ثروت يارى و همكاران رابطه معنادارى بين سبك فرزند برورى والدين با برخاشگرى و اختلالات رفتارى در كودكان به اثبات رسيد كه اين مطالعه،

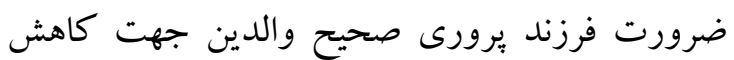
بروز مسائل رفتارى و روانى در كودكان را نشان

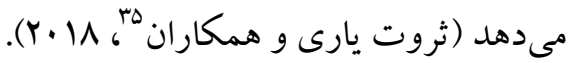
همجنين طبق جدول Fا، با توجه به نتايج آزمون كاى

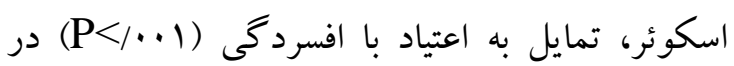
دانش آموزان، رابطه مستقيم و معنادارى داشت كه اين نتيجه نيز همسو با نتايج مطالعات ييشين از جمله

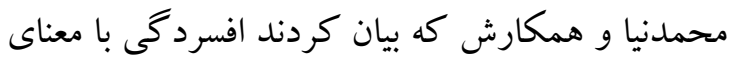

32 - Yousefi et al

33 - Amani et al

34 - Mohseni et al

35 - Servatyari et al

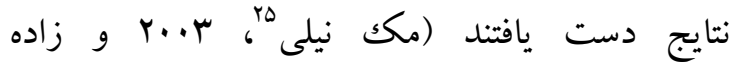

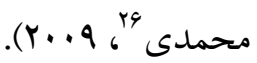
اما در اين مطالعه بين جنسيت با ميزان ناميدى رابطه معنادارى يافت نشد ( PI/91). توجيه آن را شايد بتوان به شرايط اجتماعى، اقتصادى و فرهنكى جامعه مورد نظر نسبت داد كه ميزان ناميدى در هر دو جنس تقريباً

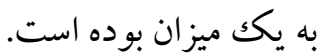

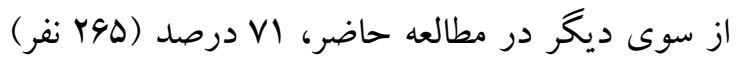
از دانش آموزان داراى ميزان افسردگى كم، إب درصد دهد

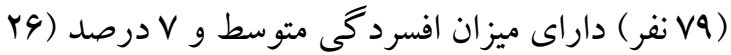

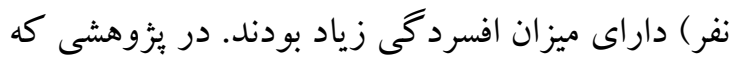
خدادادى و همكارش در دانشگاه علوم يزشكى خرم آباد روى دانشجويان انجام دادند اين ميزان براى

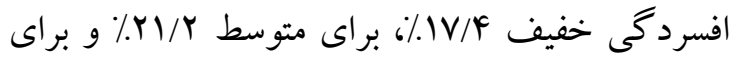

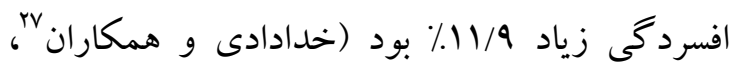

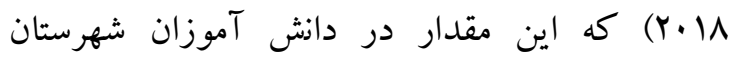
ديواندره به عنوان يكك جامعه سنتى قابـل ملاحظه است. در تحقيق حاضر با محاسبه درصد افسردگى متوسط و زياد، اين ميزان به \&ی)٪ مىرسد كه با درصد افسردگى در ديخر مطالعات تفاوت جشمخيرى دارد،

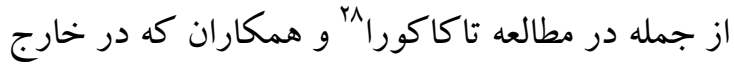

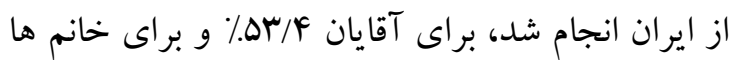

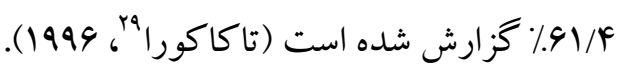
در مطالعه حاضر، افسردگى با جنسيت رابطه معنادارى

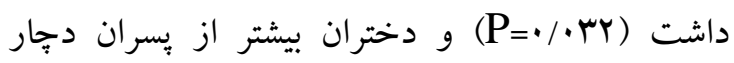

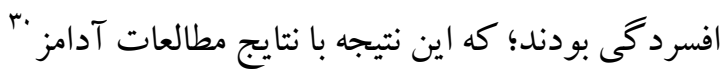

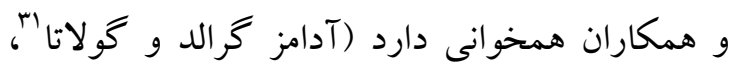
1919). از سوى ديخر در مطالعه يوسفى و همكاران

\footnotetext{
25 - McNeely

26- Zadehmohammadi

27 - Khodadadi et al

28 - Takakura

29 - Takakura

${ }^{30}$ - Adams

${ }^{3}$ - Adams Gerald \& Gullotta
} 
مدارس آموزش و يرورش جهت همكارى هاى صادقانه كمال تشكر رادارند.

\section{References}

Adams Gerald R, \& Gullotta Thomas. (1989). Adolescent life experiences: Thomson Brooks/Cole Publishing Co.

Amani F, Sohrabi B, Sadeghieh S, \& Mashoufi M. (2004). The prevalence of depression among the students of Ardabil University of Medical Sciences, 2003. Joumal of Ardabil University of Medical Sciences, 3(11), 7-11.

Beck Aaron T, Weissman A, Lester D, \& Trexler L. (1974). The measurement of pessimism: the hopelessness scale. Joumal of consulting and clinical psychology, 42(6), 861.

Berzonsky Michael D. (2003). Identity style and wellbeing: Does commitment matter? Identity, 3(2), 131-142.

Berzonsky Michael D, \& Ferrari Joseph R. (1996). Identity orientation and decisional strategies. Personality and individual Differences, 20(5), 597-606.

Dortaj F, Masaebi A, \& Asadzadeh H. (2010). The effect of anger management training on aggression and social adjustment of 12-15 years old male students. Journal of Applied Psychology, 3(4), 62-72.

Ghazinezhad M, \& Savalanpour E. (2009). Social exclusion and addiction potential among female University students in Tehran. Iranian Joumal of Social Problem, 16(3), 139-180.

Gyamerah J, \& Lantz J. (2002). Meaning, technology, and smoking cessation. Paper presented at the Intemational Fonum for Logotherapy.

Isazadegan A, Micaeili F, \& Meroei Milan F. (2014). The relationship between hope, optimism and meaning of education with academic performance in high school students. Joumal of School Psychology 3(2), 137-152.

Jon Randolph H, Bucholz Kathleen K, Theodore J, Grant Julia D, Schemer Jeffrey F, Sartor Carolyn E, ... Heat Andrew. (2010). Effect
زندگى رابطه منفى معنى دارى وجود دارد و پِ از آن

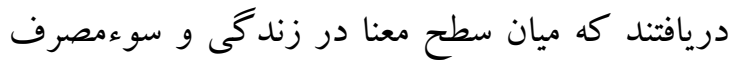
داروهاى مخدر رابطه مستقيم و معنىدارى وجود

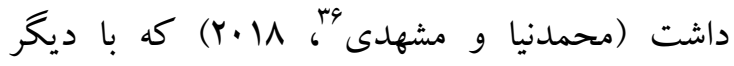

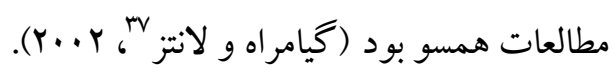

نتيجه كيرى نتيجه اينكه شناسايى و رفع عوامل مؤثر در گرىايش

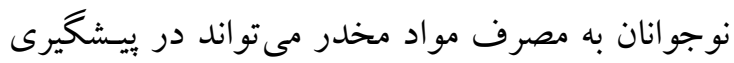
از مصرف در نوجوانان و كاهش تقاضاى مصرف مواد مخدر در بزرگكسالان بسيار مؤثر باشد. يافتهاى اين

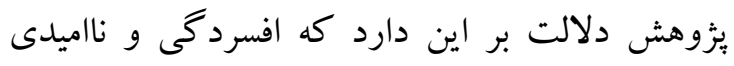

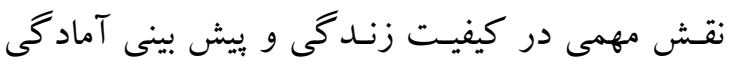
به اعتياد دارند و اينكه افراد نوجوان مورد مطالعه، در مجموع نيازمند خدمات بهداشت و روان مىباشند كه در وهله اول نيازمند توجه و حمايتهاى معنوى خانواده و سبس تدوين سياستهاى آموزشى و ييشخيرانه نهادهايى مانند آموزش و وبرورش و در مقياس كوجّك تر هر يكك از مدارس است.

\section{سياسگز ارى}

نويسندكان مقاله مراتب تشكر و قدردانى خود را از معاونت محترم تحقيقات و فناورى دانشگاه علوم يزشكى كردستان جهت حمايت هاى مالى از اين طرح ابراز مىنمايند. اين مقاله حاصل طرح تحقيقات دانشجويى مصوب كميته تحقيقات دانشجويى دانشگاه

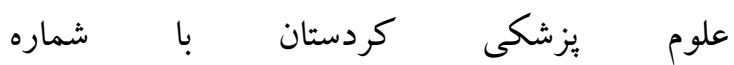

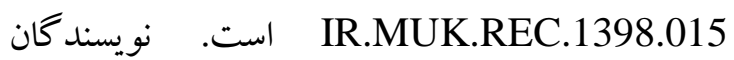
همجنين از كليه دانش آموزان، معلمان و مديران محترم

36 - Mohammad Nia \&Mashhadi

${ }^{37}$ - Gyamerah \& Lantz 
of Patemal Alcohol and Drug Dependence on Offspring Conduct Disorder: GeneEnvironment Interplay. Joumal of studies on alcohol and drugs, 71(5), 652-663.

Kaheni S. (2004). The prevention methods of the trend of young people's drug abuse. ScienceNews Joumal of Birjand's School of Nursing and Midwifery, 17(3), 25-31.

Kaplan HI. (2015). Sadock's synopsis of psychiatry: Behavioral Sciences. Clinical Psychiatry. Kaplan HI, Sadock BJ, Grebb JA. Baltimore, Williams and Wilkins, 7, 468469.

Kaviani H, \& Mousavi AS. (2008). Psychometric properties of the Persian version of Beck Anxiety Inventory (BAI). Tehran University Medical Joumal TUMS Publications, 66(2), 136-140.

Khodadadi, B., Anbari, K. H., \& Farahani, S. M. (2018). Evaluation of Anxiety, Stress and Depression among Students of Lorestan University of Medical Sciences, 2016. Journal of Research in Medical and Dental Science, 6(1), 258-294.

Koplik Elissa K, \& de Vito Anthony J. (1986). Problems of freshmen: Comparison of classes of 1976 and 1986. Joumal of College Student Personnel, 27(2), 124-131.

Mayes Alice N, \& McConatha Jasmin. (1982). Surveying student needs: A means of evaluating student services. Joumal of College Student Personnel, 23(6), 473-476.

McNeely C. (2003). Connection to school as an indicator of positive development: Division of General Pediatrics and adolescent Health, University of Minnesota.

Moddabemia MJ, Mirhosseini SK, \& Tabari R. (2013). Factors influencing addiction in people of 15 to 30 years of age: a qualitative study. Joumal of Guilan University of Medical Sciences, 22(87), 70-77.

Mohammad Beigi AAF, Mohammad Salehi N, Ghamari F, \& Salehi B. (2009). Depression symptoms prevalence, general health status and its risk factors in dormitory students of Arak universities 2008. Arak Medical University Journal, 12(3), 116-123.

Mohammad Nia Saeed, \& Mashhadi Ali. (2018). The Effect of Meaning of life on the Relationship between Attitude toward
Substance Abuse and Depression. The Neuroscience Joumal of Shefaye Khatam, 6(3), 43-51. doi:10.29252/shefa.6.3.43

Mohammadkhani S, \& Rezaei JH. (2016). Relationship between cigarette and hookah smoking with individual, family and social factors in adolescents. Journal of Sabzevar Uiversity of Medical Sciences, 23(2), 262280.

Mohseni S, Hoseini SA, Kahaki F, Hoseini F, \& Mirshekari L. (2018). Relationship between frustration, mental health and metacognition with high-risk behaviors in adolescents. nursing development in health, 9(1), 15-25.

Niaz Azari K. (2014). Effect of freshness and vitality in academic achievement in high school students in Sari. Joumal Management System, 2(3), 35-57.

Organization, W. H. (2017). Depression and other common mental disorders: global health estimates. Retrieved from

Saah, T. (2005). The evolutionary origins and significance of drug addiction. Harm reduction joumal, 2(1), 8 .

Sears K. (2007). The relationship between hope, executive function, behavioral/emotional strengths and school functioning in 5th and 6th grade students. The Ohio State University,

Servatyari K, Valizadeh Ardalan P, Yazdanpanah S, Yazdanpanah H, \& Parkalian M. (2019). The Relationship between Mobile Phone Addiction and Depression and Hopelessness among High School Students in Divandareh city in 2018. Acta Scientific Medical Sciences, 3(10), 58-64.

Servatyari, K., Mardani, N., Servatyari, B., \& Yazdanpanah, H. (2019). The study of factors affecting concentration in classroom among high school students in Divandarreh City, Iran, in 2018. Chronic Diseases Journal, 7(3), 153-159.

Servatyari, K., Valizadeh Ardalan, P., Yazdnpanah, S., Mardani, N., \& Yazdan Panah, H. (2019). Frequency of psychological disorders symptoms and their effects on high school students in Divandareh city in 2018. Shenakht Joumal of Psychology and Psychiatry, 6(3), 71-82. 
Servatyari, K., Yousefi, F., Kashefi, H., Bahmani, M. P., Parvareh, M., \& Servatyari, S. (2018). The relationship between parenting styles with the aggression of their children in sanandaj primary students. Intemational Journal of Biomedicine and Public Health, 1(3), 141-147. doi:10.22631/ijbmph.2018.117376.1018

Shahni Yeylagh M, \& Akaberian S. (2001). Effect of counseling on reducing depression and hopelessness in depressed adolescents' leukemic in Shafa Hospital at Ahwaz University of Medical Sciences. Joumal of Psychology and Educational Sciences of Shahid Chamran University of Ahvaz, 3(8), 115-134.

Snyder CR. (2005). Measuring hope in children. In What do children need to flourish? (pp. 6173): Springer.

Takakura, M., Taira, K, Shinya, N., \& Miwa, K. (1996). Prevalence of depressive symptoms and its relation to demographic variables in high school students. [Nihon koshu eisei zasshi] Japanese joumal of public health, 43(8), 615-623.

Taremian, F., Bolhari, J., Pairavi, H., \& Ghazi Tabatabaeii, M. (2008). The prevalence of drug abuse among university students in
Tehran. Iranian Joumal of psychiatry and clinical psychology, 13(4), 335-342.

Yousefi, F., Shahvesi, S., Shahvisi, M., \& Servatyari, K. (2017). The Relationship between Gender Difference and the History of Psychiatric Disorders in the Family with Oppositional defiant disorder among Primary School Students in Sanandaj in 2014. Shenakht Joumal of Psychology and Psychiatry, 4(3), 58-64.

Zadehmohammadi, A. (2009). Enquiring the effect of family structure, family environment and school connection on risk taking of high school students in Tehran. Family Research Center, University; ShahidBeheshti-Tehran.

Zarepoor F, Kamali M, Alagheband M, Gheisari M, \& Sarlak S. (2012). Evaluation of depression and its relationship to exercise in women over 20 years. Joumal of Shahid Sadoughi University of Medical Sciences, 20(1), 64-72.

Zargar Y, Najarian B, \& Naami AZ. (2008). The relationship of some personality variables, religious attitudes and marital satisfaction with addiction potential in personnel of an industrial factory in Ahvaz. Joumal of Education Journal of Education and Psychology, 15(1), 99-120. 